\title{
The Effect of the Fracture Types on the Activity Daily Living and Mortality in Geriatric Patients
}

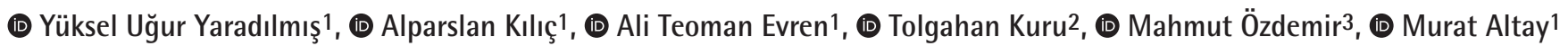 \\ 1 University of Health Sciences Turkey, Keçiören Health Practice and Research Center, Clinic of Orthopaedics and Traumatology, Ankara, Turkey \\ ${ }^{2}$ Çanakkale Onsekiz Mart University Faculty of Medicine, Department of Orthopaedics and Traumatology, Çanakkale, Turkey \\ 3VM Medical Park Pendik Hospital, Clinic of Orthopaedics and Traumatology, Ankara, Turkey
}

\begin{abstract}
Objective: Knowledge of the frequency of geriatric fracture types and independency life rates will provide insights on its prevention in the community. Our study aimed to determine the effect of fracture types on the loss of activity daily living and mortality with a one-year follow-up.

Materials and Methods: This study included a total of 522 patients (>65 years of age) with extremity and axial skeletal fractures. Fractures were classified according to location into 17 types. The incidence of the fracture types, hospitalization and operation rates in geriatric fractures were defined. Barthel and Katz indexes were evaluated for Basic activity daily living scale (BADLs) at the final control. The relationship between fracture types and mortality and decrease of BADLs was determined.

Results: The mean age of the patients was $76.24 \pm 7.6$ (range: $65-96$ ) and the female-to-male ratio was $7 / 3$. Four fracture types which constitute $60 \%$ of the fractures were noted: Hip fracture $(29.5 \%)$, vertebra fracture $(7 \%)$, distal radius fracture $(16 \%)$, and proximal humerus $(8 \%)$. The mortality was noted in $21 \%$ of the patients. Mortality ratio and BADLs were statistically different according to the fracture types. The hip, vertebra, and femur fractures had lower Barthel index compared to other fractures.
\end{abstract}

Conclusion: High functional dependency and mortality were found in the patients with geriatric fracture, especially in the hip, femur and vertebra fractures. The patients have upper extremity fractures can reach the highest value of BADLs at one-year follow-up.

Keywords: Geriatric fractures, activity daily living, Katz index, Barthel index, mortality

\section{Introduction}

In the elderly population, an increase in bone porosity and a decrease in bone tissue proportion are expected (1). In addition, falling is a health problem with a multifactorial etiology, especially over the age of 65 (2). Fractures are more common in older ages, because of lower bone quality and higher frequency of falls. Over the age of 65 , the incidence of fractures is four times higher (3). With a worldwide aging population, the importance of the prevention and management of osteoporotic fragility fractures has been emphasized over time.

Hip fractures, distal radius fractures, proximal humerus fractures, and vertebral fractures are the most common four types of geriatric fractures (4-6). While most of the fractures are seen commonly in males, the incidence of fractures in older ages is two times higher in females than in males (7). Another prominent feature in elderly fractures is that while the upper extremity fractures are often treated conservatively, the lower extremity fractures, especially the hip fractures, require hospitalization and surgical intervention (8).

Geriatric fractures are commonly evaluated with health-related quality of life (Ool) instruments, such as short form 36 of the medical outcomes study (SF-36), short-form 12 of the medical outcomes study (SF-12), and EuroOol (EQ-5D) SF-12 $(9,10)$. An important deficiency in the literature regarding geriatric fractures is the fact that the relationship between fracture type and activity daily living (ADL) and mortality in geriatric patients

Address for Correspondence: Yüksel Uğur Yaradılmış, University of Health Sciences Turkey, Keçiören Health Practice and Research Center,

Clinic of Orthopaedics and Traumatology, Ankara, Turkey

Phone: +90 5327697802 E-mail: ugur_yaradilmis@outlook.com ORCID: orcid.org/0000-0002-7606-5690

Received: 05.08.2021 Accepted: 28.12.2021

Cite this article as: Yaradılmış YU, Kılıç A, Evren AT, Kuru T, Özdemir M, Altay M. The Effect of the Fracture Types on the Activity Daily Living and Mortality in

Geriatric Patients. Eur J Geriatr Gerontol 2022;4(2):52-57

๑Copyright 2022 by the Academic Geriatrics Society / European Journal of Geriatrics and Gerontology published by Galenos Publishing House. 
is yet not to be investigated. Another point is the inadequacy of literature regarding the epidemiological study of fractures. Geriatric fractures have been examined with its subtypes and hip fractures subtypes was shown to emphasize their high mortality and morbidity (7). Alarkawi et al. (11) made attention to the adequate research on fractures besides hip and vertebra fractures. This elderly group experience many comorbidities and major problems, such as osteoporosis and sarcopenia, which are difficult to change $(12,13)$. Perhaps it is important that they can continue their independent life and these patients should be evaluated with ADL.

Knowledge of the frequency of geriatric fracture types and independency life rates will provide insights on its prevention in the community as well as aid the determination of effective treatment strategies.

Our study determined the epidemiological characteristics of geriatric fractures and the effect of fracture types on loss of daily life activities and mortality with one-year follow-up.

\section{Materials and Methods}

\section{Patients}

In this study, a total of 535 patients (over 65 years of age) who were diagnosed with fractures in orthopedics and traumatology clinic between January and December 2019 were retrospectively analyzed. Multiple fractures $(n=8)$ and periprosthetic fractures $(n=5)$ were excluded. A total of 522 patients with extremity and axial skeletal fractures were included in this study (Figure 1). Fractures were classified into 17 types as to their locations (Table 1). The incidence of the fracture types among geriatric patients was defined. Epidemiological data of these patients, including age, gender, and comorbidities.

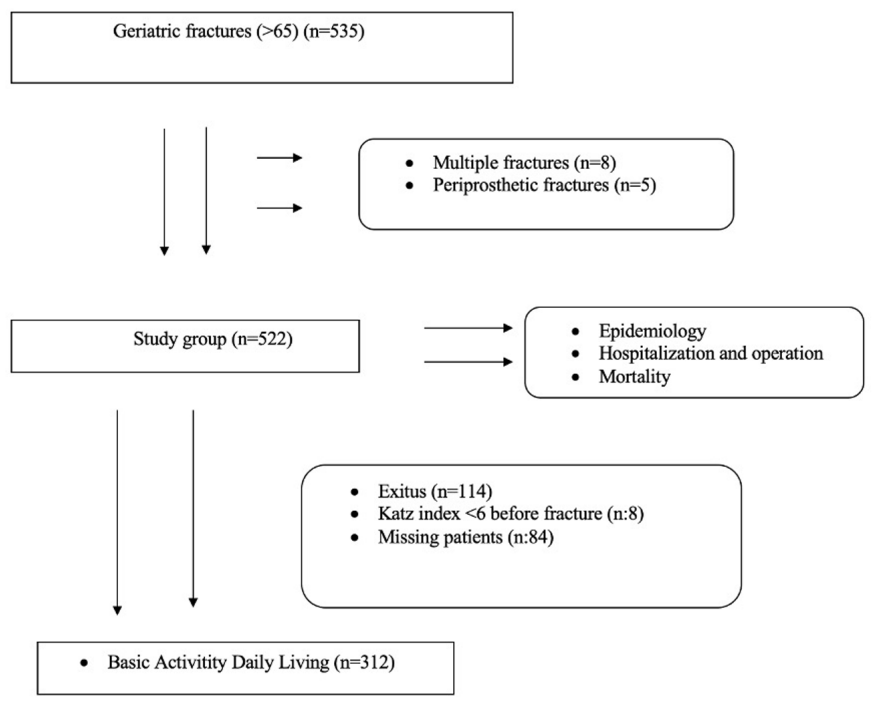

Figure 1. Flow chart of patients enrolled in the study

\section{Hospitalization and operation}

General and extremity examinations were performed in the emergency department. Hospitalization was applied to patients who had surgical indications according to the fracture site and who were vitally unstable or expected to have instabile fracture. Patients who did not require surgical intervention and were vitally stable were discharged with their specific recommendations. Surgical treatment was done after hospitalization in line with the anesthesia risk ratio and patient approvals. Mechanical and medical deep venous thrombosis prophylaxis was administered immediately after hospitalization. Hospitalization and operation ratio of the fractures were determined.

\section{Mortality}

Mortality was evaluated in 522 included patients. The exitus patients' data were collected from the death reporting system record. Besides fracture types, other variables relationship between mortality was determined.

\section{ADL}

A basic ADL scale (BADLs) was applied to the patients at the final control (12-24 months). Barthel and Katz indexes were evaluated for basic ADLs $(14,15)$. The Katz index measures six

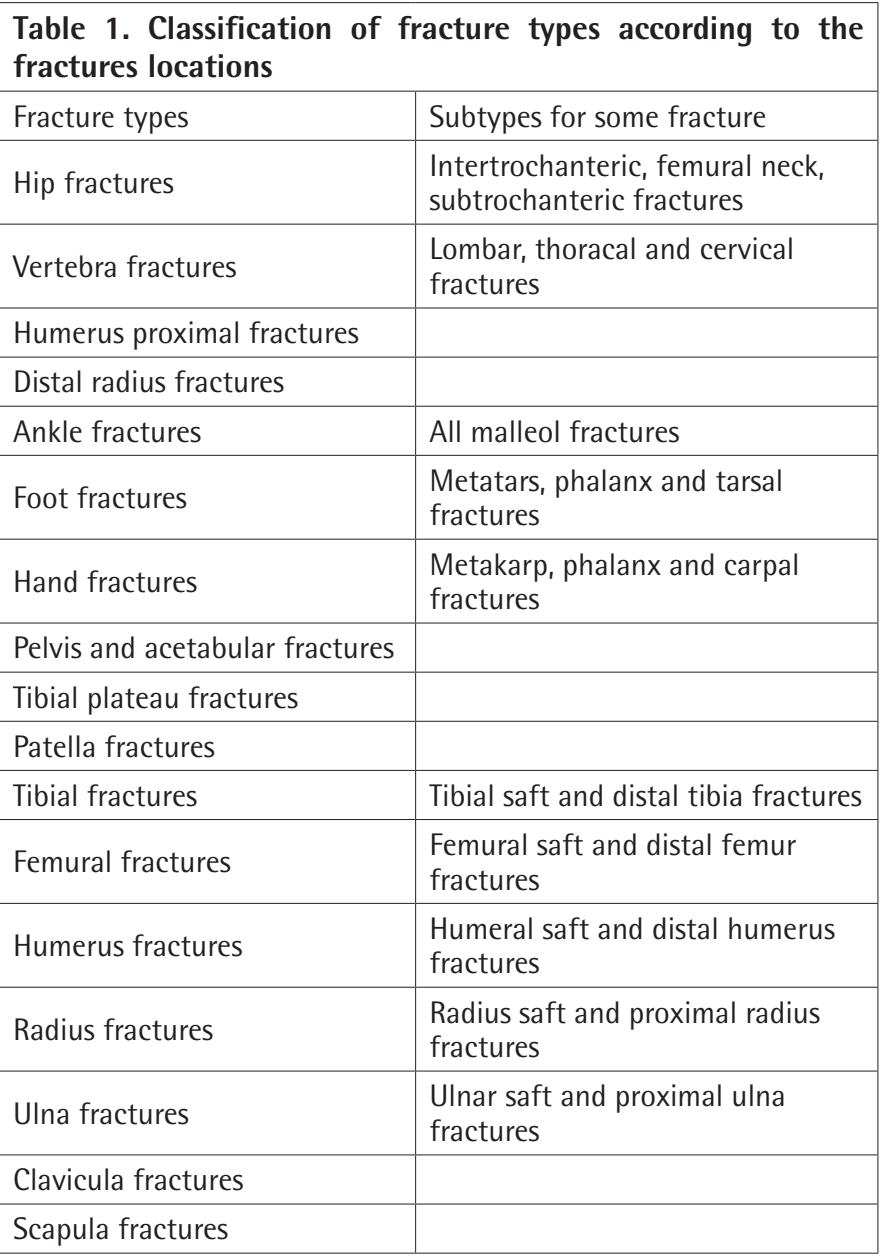


items: Bathing, dressing, toileting, transferring (bed to chair and back), maintaining continence and feeding. Each of items was evaluated with one point, with a maximum of 6 points being obtainable. Functional independent patient is indicated by a Katz index of 6 , while a functional dependent patient is indicated by a Katz index $<6$. validity and reliability of the Turkish version of Katz index evaluated in healthy volunteers after 65 years of age Arik et al. (16). The Barthel index comprises 10 items (feeding, bathing, groomimg, dressing, bowel control, bladder control, toilet use, transfers, mobility on level surcafes and stairs) with a maximum of 100 points being obtainable. Validity and reliability of the Turkish version of Barthel index was assessed by Küçükdeveci et al. (17). A total of 114 exitus patients, patients with Katz index $<6$ before fracture $(n=8)$, and missing patients $(n=84)$ were excluded for BADLs evaluation. BADLs was performed for 312 patients (Figure 1). The relationship between fracture types and decrease of BADLs was determined.

\section{Statistics}

Data obtained in the study were analyzed statistically using SPSS v.22 software, and at a confidence interval of 95\%. Qualitative data were stated as frequency distribution and quantitative data were stated as mean, minimum and maximum values. The $\chi^{2}$ test was applied to categorical data and the Student's t-test to quantitative data. Normality of data distribution was tested with the Shapiro-Wilk test. Demografic values were evaluated with the Mann-Whitney $U$ test. Mortality, Barthel and Katz

\begin{tabular}{|c|c|c|}
\hline & $n=522$ & Frequency \\
\hline Age & $76.24 \pm 7.6(65-96)$ & \\
\hline $65-75$ & 247 & $45.5 \%$ \\
\hline $75-85$ & 196 & $36 \%$ \\
\hline$>85$ & 100 & $18.5 \%$ \\
\hline \multicolumn{3}{|l|}{ Gender } \\
\hline Female/male & $384 / 159$ & \\
\hline Follow-up & $16 \pm 1(12-24)$ & \\
\hline \multicolumn{3}{|l|}{ Side } \\
\hline Right/left & $266 / 237$ & \\
\hline Vertebra & 36 & \\
\hline \multicolumn{3}{|l|}{ Subtype } \\
\hline Upper extremity & 190 & $35 \%$ \\
\hline Lower extremity & 290 & $53 \%$ \\
\hline Vertebra & 37 & $7 \%$ \\
\hline Pelvis-acetabulum & 25 & $5 \%$ \\
\hline \multicolumn{3}{|l|}{ Season } \\
\hline Summer & 147 & $29 \%$ \\
\hline Spring & 157 & $27 \%$ \\
\hline Winter & 123 & $23 \%$ \\
\hline Autumn & 116 & $21 \%$ \\
\hline
\end{tabular}

index of the fractures were evaluated with the Kruskal-Wallis. The relationship between fractures types and mortality, and Katz index evaluated with the Mann-Whitney $U$ test and chi-square test. A value of $p<0.05$ was accepted as statistically significant.

\section{Results}

Mean age of the patients was $76.24 \pm 7.6$ (range: $65-96)$ and female-to-male ratio was $7 / 3$. There were $53 \%$ lower extremity fractures, 35\% upper extremity fractures, 7\% vertebra fractures and 5\% pelvis-acetabular fractures. The demographic data of the patients are presented in Table 2. While $37.5 \%$ of the patients were hospitalized, $32.5 \%$ of the patients were operated. The mortality ratio was $21 \%$.

Four fracture types, which constitute 60\% of the fractures were noted: Hip fractures (29.5\%), vertebra fractures (7\%), distal radius fractures $(16 \%)$ and proximal humerus fractures (8\%). Frequency of the geriatric fractures are presented in Figure 2.

The hospitalized patients with hip fractures were $72.5 \%$ and other fracture types hospitalized are given in Figure 3. Only 6\% of the patients with upper extremity fractures underwent surgery. The mean follow-up period of the patients was 16 (range: 1224) months and the mortality ratio was $21 \%$. The mortality ratios in the fracture types respectively; hip $46 \%(n=72)$, pelvisacetabular 34\% $(n=9)$, vertebra $20 \%(n=8)$, tibia plateau $34 \%$ $(n=4)$, ankle $14 \%(n=6)$, proximal humerus $25 \%(n=9)$ and distal radius fractures $6 \%(n=4)$. There was a statistical difference between mortality and fracture types $(p<0.05)$. Mortality was affected by variables such as age, comorbidity, and operation (Table 3).

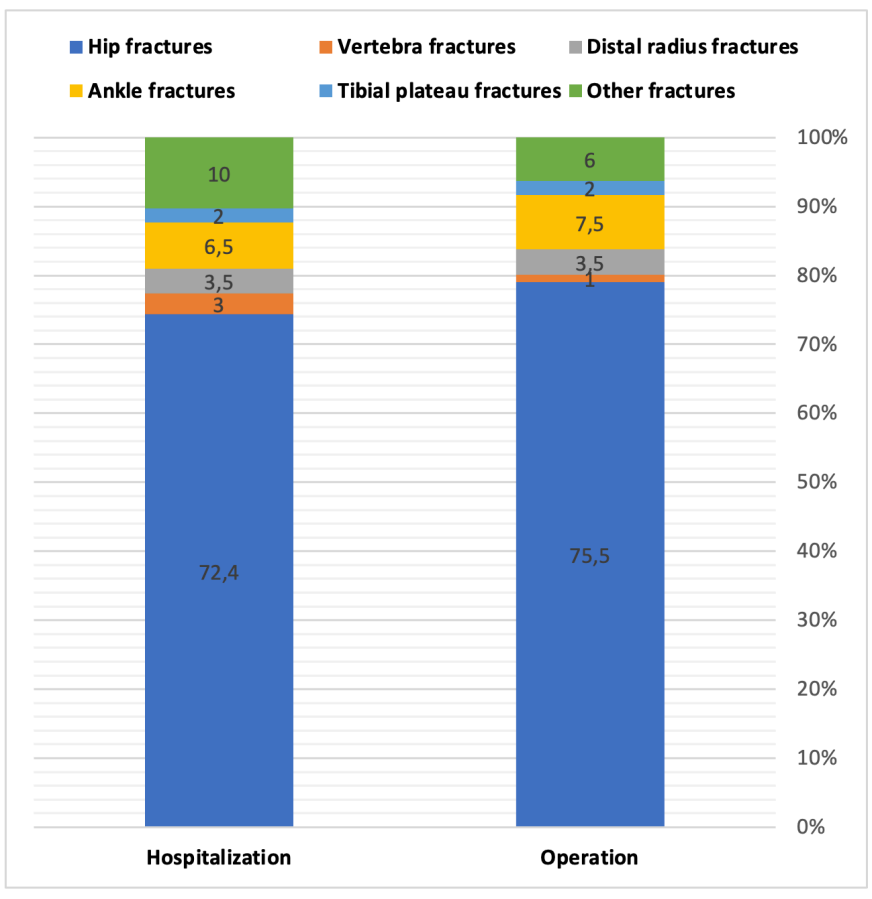

Figure 3. Hospitalization and operation of the fracture types 


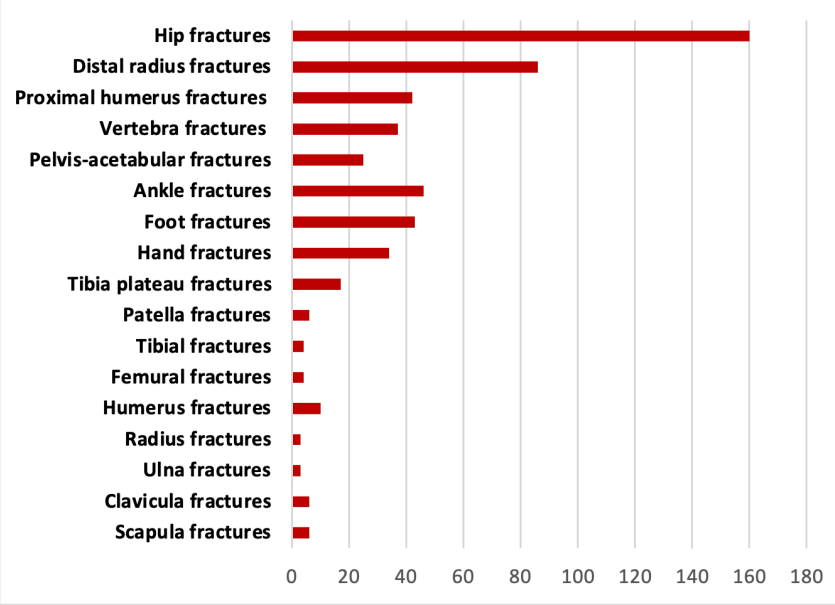

Figure 2. Frequency of fractures types

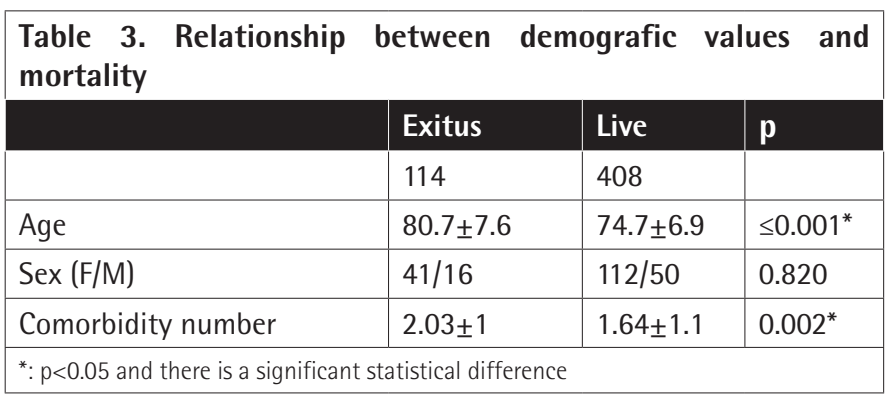

While $75 \%$ of the patients had a Katz index of 6 point, 25\% of the patients were not completely functionally independent. Regarding the Barthel index values, 70\% of the patients had 100 points. There was a statistical difference between BADLs and fracture types (Table 4). Barthel index was lower in the patients with hip, vertebra, and femoral fractures than other fractures. Katz index was affected by variables such as age, comorbidity, and operation (Table 5).

\section{Discussion}

Aging is associated with a higher fracture risk and diminished capacity of bone to heal. Bone fractures are common in the elderly, with residual lifetime fracture risk in a person aged 60 years reported to be $29 \%$ in males and $56 \%$ in females (18). Regeneration of bone defects often presents significant challenges, particularly in these patients with decreased tissue regeneration capacity (19). Many cases of delayed union and non-union are idiopathic in nature, several reports have suggested that these complications are more common in the elderly (20). Geriatric fractures can lead to work absence, decreased productivity, disability, impaired Qol, health loss, and high health-care costs and are a major burden to individuals, families, societies, and health-care systems (21). Our study aimed to determine the frequency of geriatric fracture types and effect of fracture types on loss of ADL and mortality with one-year follow-up.

\begin{tabular}{|l|l|l|l|}
\hline \multicolumn{4}{|c|}{ Table 4. Basic activity of daily life of fracture types } \\
\hline & $\begin{array}{l}\text { Frequency } \\
\text { (n=512) }\end{array}$ & $\begin{array}{l}\text { Barthel } \\
\text { (n=312) }\end{array}$ & $\begin{array}{l}\text { Katz } \\
\text { (n=312) }\end{array}$ \\
\hline Total & & $95 \pm 11.4$ & $5.5 \pm 1$ \\
\hline P-value & $29.5 \%$ & $0.005^{*}$ & $0.004^{*}$ \\
\hline Hip fractures & $7 \%$ & $90.7 \pm 14.1$ & $5 \pm 1.3$ \\
\hline Vertebra fractures & $16 \%$ & $98.7 \pm 19.5$ & $5.1 \pm 1.4$ \\
\hline Distal radius fractures & $8 \%$ & $93 \pm 11.7$ & $5.9 \pm 0.3$ \\
\hline Proximal humerus fractures & $8.3 \pm 1$ \\
\hline Pelvis-acetabular fractures & $5 \%$ & $98 \pm 4.4$ & $5.8 \pm 0.4$ \\
\hline Tibial plateau fractures & $3 \%$ & $94 \pm 8.9$ & $5.4 \pm 0.9$ \\
\hline Patella fractures & $1 \%$ & 100 & 6 \\
\hline Ankle fractures & $8.5 \%$ & 100 & 6 \\
\hline Hand fractures & $6.3 \%$ & 98.5 & 5.8 \\
\hline Foot fractures & $7.9 \%$ & 100 & 6 \\
\hline Tibial fractures & $1 \%$ & 90 & 5 \\
\hline Femural fractures & $1 \%$ & 90 & 5 \\
\hline Humerus fractures & $2 \%$ & 100 & 6 \\
\hline Radius fractures & $1 \%$ & 100 & 6 \\
\hline Ulna fractures & $1 \%$ & 100 & 6 \\
\hline Clavicula fractures & $1 \%$ & 100 & 6 \\
\hline Scapula fractures & $1 \%$ & 100 & 6 \\
\hline$*$ p<0.05 and there is a significant statistical difference & \\
\hline & & & \\
\hline
\end{tabular}

Table 5. Relationship between demografic values and basic activity of daily life

\begin{tabular}{|l|l|l|l|}
\hline & Katz index $<\mathbf{6}$ & $\begin{array}{l}\text { Katz } \\
\text { index=6 }\end{array}$ & p \\
\hline Age & 74 & 238 & \\
\hline Sex (F/M) & $78.5 \pm 7$ & $73.5 \pm 6.5$ & $\leq 0.001^{*}$ \\
\hline Comorbidity number & $25 / 12$ & $82 / 37$ & 0.878 \\
\hline *: $p<0.05$ and there is a significant statistical difference & $2.2 \pm 1.2$ & $\leq 0.001^{*}$ \\
\hline
\end{tabular}

In studies regarding aged-related fractures, hip fractures, vertebral fractures, and distal radius fractures are common fractures. The incidence of fractures is affected by geographic, ethnic, and socio-economic factors (22). While hip fractures are 11 times more incident in European countries, vertebral fractures were 3 times more incident in Scandinavian countries (23). Geriatric cases were most commonly located at the femur $(43.4 \%)$, followed by radius $(11.8 \%)$, humerus $(10.6 \%)$, and lumbar vertebra (3\%). Fractures in geriatric cases are most commonly seen in women (61\%), among those treated surgically (67\%), and during winter (32.9\%). In incident studies, diagnostic determination of vertebral fractures is difficult, since they are ignored over time and since no further examinations are performed (8). In our study, the four most common fractures were respectively: Hip fractures (29.5\%), distal radius fractures $(16 \%)$, proksimal humerus fractures $(8 \%)$ and vertebra fractures 
(7\%). In addition, it was seen 2 times more frequently in women. Geritric fractures are more common in summer and spring, but less common in winter and autumn in our study.

Aged-related fractures have never been evaluated with BADL. Katz and Barthel indexes are often used for BADL. Barthel index is one of the most widely-used tools for assessment of functional independence (14). Küçükdeveci et al. (17) in patients with stroke and spinal cord injury. Katz index is a shorter assessment and may be easier for patients (15). Arik et al. (16) determined after 65 years of age the Katz index as $4.7 \pm 1.6$ and the Barthel index as $86 \pm 25$. In our study were found Katz index as $5.5 \pm 1$ and Barthel index as $95 \pm 11.4$ for geriatric fractures. In line with these values, it is important to note that the rate of complete independence was low in the patients $>75$ years old. In our study, mild dependence (range: 62-90) was observed in vertebral, hip, and femur fractures according to the Barthel index, while complete independence (range: 91-99) was observed in other fractures. In a prospective evaluation of hip fractures, low ADL values was observed and the mortality rate of these patients was determined (24). In another study, ADL and Charlson comorbidity scores were used during follow-up to determine re-hospitalization after hip surgery (25).

Fractures are more mortal among the elderly than in normal population (11). Hip and vertebral fractures cause more morbidity and mortality than other fractures $(26,27)$. There is limited information about the effect of several fractures on mortality, except for vertebra and hip fractures. Alarkawi et al. (11), in their study, mentioned the significant effect of proximal, non-hip, non-vertebra fractures, and subsequent fractures on mortality, excluding hip fractures. Although mortality is most common in lower extremity fractures; resulted in mortality in $46 \%$ of patients with hip fractures and 34\% of patients with pelvis fractures in our study. On the other hand, 20\% mortality was observed in vertebral fractures and it was not higher than expected. Apart from the type of fracture, variables such as advanced age and comorbidity, also increase mortality. Hip fractures have been frequently investigated in the literature because they are both common and mortal in the elderly. Mortality has been found in many studies to correlate with age and comorbid conditions such as chronic liver, kidney, or cardiovascular diseases and pneumonia and dementia in hip fractures $(28,29)$. The other factors associated with mortality were cognitive impairment, delirium, living with caregiver, smoking and poor function before fracture $(29,30)$. When evaluating mortality for elderly patients, it is necessary to consider a lot of risk factors.

\section{Study Limitations}

This study has several limitations, which include collection of data from a single center and its retrospective design. This study is innovative due to its inclusion of all fracture types and the questioning ADLs; however, the addition of multi-center studies with more patients in the future will increase the reliability and generalizability of the data. Another limitation of this study is the lack of data on status of patients in terms of osteoporosis.

\section{Conclusion}

Hip fractures in the geriatric forties constitute a major burden in Turkish population. High functional dependency and mortality are expected due to patients with geriatric fractures, especially the hip, femur, and vertebra fractures. The patients have upper extremity fractures can reach a high rate of full BADLs at one year follow up.

\section{Ethics}

Ethics Committee Approval: The study was approved by the Review Board and Commission of Keçiören Health Practice and Research Hospital in Turkey (approval date: 04.03.2021 number: 73-929).

Informed Consent: Written informed consent was obtained from participants.

Peer-review: Externally peer-reviewed.

\section{Authorship Contributions}

Surgical and Medical Practices: Y.U.Y., A.K., M.A., Concept: Y.U.Y., A.K., A.T.E., T.K., M.Ö., M.A., Design: Y.U.Y., A.K., M.A., Data Collection or Processing: Y.U.Y., A.K., M.A., Analysis or Interpretation: Y.U.Y., A.K., A.T.E., T.K., M.Ö., M.A., Literature Search: Y.U.Y., A.T.E., T.K., M.Ö., M.A., Writing: Y.U.Y., A.T.E., T.K., M.Ö., M.A.

Conflict of Interest: No conflict of interest was declared by the authors.

Financial Disclosure: The authors declared that this study received no financial support.

\section{References}

1. Schuit SCE, van der Klift,M, Weel AEAM, de Laet CEDH, Burger H, Seman E, Hofman A, Uitterlinden AG, van Leeuwen JPTM, Pols HAPS. Fracture incidence and association with bone mineral density in elderly men and women: The Rotterdam Study. Bone 2004;34:195-202.

2. Yu WY, Hwang HF, Hu MH, Chen CY, Lin MR. Effects of fall injury type and discharge placement on mortality, hospitalization, falls, and ADL changes among older people in Taiwan. Accid Anal Prev 2013;50:887-894.

3. Gosch M, Kammerlander C, Neuerburg C. [Osteoporosis-epidemiology and quality of care]. Z Gerontol Geriatr 2019;52:408-413.

4. Gül D, Akpancar S. Fractures in Geriatric Cases. Journal of Geriatric Science 2019;2:14-19.

5. De Laet CE, Pols HA. Fractures in the elderly: epidemiology and demography. Baillieres Best Pract Res Clin Endocrinol Metab 2000;14:171-179.

6. Baidwan NK, Naranje SM. Epidemiology and recent trends of geriatric fractures presenting to the emergency department for United States population from year 2004-2014. Public Health 2017;142:64-69. 
7. Alexiou KI, Roushias A, Varitimidis SE, Malizos KN. Quality of life and psychological consequences in elderly patients after a hip fracture: a review. Clin Interv Aging 2018;13:143-150.

8. Clynes MA, Harvey NC, Curtis EM, Fuggle NR, Dennison EM, Cooper C. The epidemiology of osteoporosis. Br Med Bull 2020;133:105-117.

9. Hallberg I, Rosenqvist AM, Kartous L, Löfman O, Wahlström O, Toss G. Health-related quality of life after osteoporotic fractures. Osteoporos Int 200415:834-841.

10. Lips $\mathrm{P}$, van Schoor NM. Quality of life in patients with osteoporosis. Osteoporos Int 2005;16:447-455.

11. Alarkawi D, Bliuc D, Tran T, Ahmed LA, Emaus N, Bjørnerem A, Jørgensen L, Christoffersen T, Eisman JA, Center JR. Impact of osteoporotic fracture type and subsequent fracture on mortality: the Troms $\varnothing$ Study. Osteoporos Int 2020;31:119-130.

12. Liu J, Curtis EM, Cooper C, Harvey NC. State of the art in osteoporosis risk assessment and treatment. J Endocrinol Invest 2019;42:1149-1164.

13. Messina C, Maffi G, Vitale JA, Ulivieri FM, Guglielmi G, Sconfienza LM. Diagnostic imaging of osteoporosis and sarcopenia: a narrative review. Quant Imaging Med Surg 2018;8:86-99.

14. Mahoney Fl, Barthel DW. Functional evaluation: the Barthel index. Md State Med J 1965;14:61-65.

15. Katz S, Ford AB, Moskowitz RW, Jackson BA, Jaffe MW. Studies of illness in the aged. The index of ADL: a standardized measure of biological and psychosocial function. JAMA 1963;185:914-919.

16. Arik G, Varan HD, Yavuz BB, Karabulut E, Kara O, Kilic MK, Kizilarslanoglu MC, Sumer F, Kuyumcu ME, Yesil Y, Halil M, Cankurtaran M. Validation of Katz index of independence in activities of daily living in Turkish older adults. Arch Gerontol Geriatr 2015;61:344-350.

17. Küçükdeveci AA, Yavuzer $G$, Tennant $A$, Süldür N, Sonel $B$, Arasil T. Adaptation of the modified Barthel index for use in physical medicine and rehabilitation in Turkey. Scand J Rehabil Med 2000;32:87-92.

18. Jones G, Nguyen T, Sambrook PN, Kelly PJ, Gilbert C, Eisman JA. Symptomatic fracture incidence in elderly men and women: the Dubbo Osteoporosis Epidemiology Study (DOES). Osteoporos Int 1994;4:277-282.

19. Gruber $R$, Koch $H$, Doll BA, Tegtmeier $F$, Einhorn TA, Hollinger JO. Fracture healing in the elderly patient. Exp Gerontol 2006;41:1080-1093.
20. Foulke BA, Kendal AR, Murray DW, Pandit H. Fracture healing in the elderly: A review. Maturitas 2016:49-55.

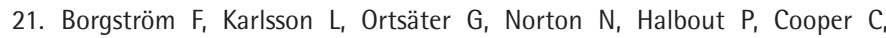
Lorentzon M, McCloskey EV, Harvey NC, Javaid MK, Kanis JA; International Osteoporosis Foundation. International Osteoporosis Foundation. Fragility fractures in Europe: burden, management and opportunities. Arch Osteoporos 2020;15:59.

22. Fuggle NR, Curtis EM, Ward KA, Harvey NC, Dennison EM, Cooper C. Fracture prediction, imaging and screening in osteoporosis. Nat Rev Endocrinol 2019;15:535-547.

23. Kanis JA, Oden A, McCloskey EV, Johansson H, Wahl DA, Cooper C; IOF Working Group on Epidemiology and Quality of Life. A Systematic review of hip fracture incidence and probability of fracture worldwide. Osteoporos Int 2012;23:2239-2256.

24. Aarden JJ, van der Esch M, Engelbert RHH, van der Schaaf M, de Rooij SE, Buurman BM. Hip Fractures in Older Patients: Trajectories of Disability after Surgery. J Nutr Health Aging 2017;21:837-842.

25. da Casa C, Pablos-Hernández C, González-Ramírez A, Julián-Enriquez JM, Blanco JF. Geriatric scores can predict long-term survival rate after hip fracture surgery. BMC Geriatr 2019;1;19:205.

26. Dennison E, Cole Z, Cooper C. Diagnosis and epidemiyology of osteoporosis. Curr Opin Rheumatol 2005;17:456-461.

27. Melton $\sqcup$, Achenbach SJ, Atkinson EJ, Therneau TM, Amin S. Long-term mortality following fractures at different skeletal sites: a population-based cohort study. Osteoporos Int 2013;24:1689-1696.

28. Yong EL, Ganesan G, Kramer MS, Howe TS, Koh JSB, Thu WP, Logan S, Cauley JA, Tan KB. Risk Factors and Trends Associated With Mortality Among Adults With Hip Fracture in Singapore. JAMA Netw Open 2020;3:e1919706.

29. Chang W, Lv H, Feng C, Yuwen P, Wei N, Chen W, Zhang Y. Preventable risk factors of mortality after hip fracture surgery: Systematic review and metaanalysis. Int J Surg 2018;52:320-328.

30. Liu Y, Wang Z, Xiao W. Risk factors for mortality in elderly patients with hip fractures: a meta-analysis of 18 studies. Aging Clin Exp Res 2018;30:323330. 